\title{
Simpanan Karbon Enhalus acoroides LF. Royle 1839 (Angiosperms: Hydrocharitaceae) di Pantai Gelaman dan Pantai Alang-Alang, Karimunjawa Jepara
}

\author{
Viny Ratnasari*, Ali Djunaedi, Adi Santoso \\ Departemen IImu Kelautan, Fakultas Perikanan dan IImu Kelautan, Universitas Diponegoro \\ Jl. Prof.H.Soedarto S.H, Tembalang,Semarang, Jawa Tengah 50275 Indonesia \\ *Corresponding author, e-mail: vinyratnasari@gmail.com
}

\begin{abstract}
ABSTRAK: Perubahan iklim disebabkan oleh berbagai aktifitas kegiatan manusia yang menghasilkan gas karbon diokasida ke atmosfer bumi yang akan berdampak pada pemanasan global. Ekosistem padang lamun memiliki kemampuan untuk menyerap dan menyimpan karbon dalam jumlah besar dari atmosfer yang dapat mengurangi emisi karbon. Tujuan penelitian ini untuk mengetahui kerapatan, tutupan lamun, biomassa dan simpanan karbon pada lamun Enhalus acoroides di Pantai Gelaman dan Pantai Alang-Alang. Penelitian menggunakan metode survei dan penentuan lokasi dipilih dengan menggunakan metode line transect quadrant yang mengacu pada metode LIPI. Sampling dilakukan pada titik $50 \mathrm{~m}$ setiap substasiun dengan metode pencuplikan. Pengukuran karbon pada sampel lamun menggunakan metode LOI.Kerapatan lamun di Stasiun 1 sebesar $1235 \mathrm{ind} / \mathrm{m}^{2}$ dan nilai tutupan lamun sebesar 68,76\%. Kerapatan Stasiun 2 sebesar 1135 ind $/ \mathrm{m}^{2}$ dan tutupan lamun sebesar $51,78 \%$. Nilai rata-rata estimasi simpanan karbon lamun Enhalus acoroides di Stasiun 1sebesar $119.27 \mathrm{gC} / \mathrm{m}^{2}$ dan di Stasiun 2 sebesar $91.57 \mathrm{gC} / \mathrm{m}^{2}$.
\end{abstract}

Kata kunci: Lamun; Biomassa; Simpanan Karbon; Karimunjawa

\section{Carbon Savings Estimated at Enhalus Acoroides LF. Royle 1839 (Angiosperms : Hydrocharitaceae) in Gelaman Beach and Alang-Alang Beach in Karimunjawa Jepara}

\begin{abstract}
Climate change is caused by various human activities that produce carbon dioxide gas into the earth atmosphere which will have an impact on global warming. Seagrass ecosystem is able to absorb and store large number of carbon from the atmosphere that can reduce carbon emissions. This research were to determine the density, seagrass cover, biomass and carbon storage in seagrasses at Gelaman Beach (Station 1) and Alang-Alang Beach (Station 2). Survey and sampling. Were conducted using quadrant transect referring to LIPI method. Observation of the density value, the percentage of seagrass coverage was conducted in all points, while the sampling was conducted at the point $50 \mathrm{~m}$ on each substation by sampling method. Carbon measurement in seagrass sample used LOI method. Total seagrass density in Station 1 was $1235 \mathrm{ind} / \mathrm{m}^{2}$ and the total value of seagrass percentage cover was 68,76\%. Total seagrass density in Station 2 was 1135 ind $/ \mathrm{m}^{2}$ and total value of seagrass percentage cover was $51,78 \%$. Average value for carbon savings estimated seagrass Enhalus acoroides in Station 1 was $119.27 \mathrm{gC} / \mathrm{m}^{2}$ and Station 2 was $91.57 \mathrm{gC} / \mathrm{m}^{2}$.
\end{abstract}

Keywords: Seagrass; Biomass; Carbon Storage; Karimunjawa

\section{PENDAHULUAN}

Lamun termasuk ke dalam tumbuhan angiospermae atau tumbuhan berbunga. Lamun memiliki daun, batang dan akar sejati yang telah berdaptasi untuk hidup di dalam air laut (Tuwo, 2011). Fungsi ekologis lamun yaitu sebagai tempat hidup, pemijahan, pengasuhan, mencari makan, produsen primer dan penangkap sedimen (Kordi, 2011). Selain fungsi tersebut, dalam beberapa tahun terakhir ini peran padang lamun merupakan salah satu penyerap emisi karbon di perairan laut (Kiswara, 2010). Lamun memanfaatkan karbon dioksida untuk proses fotosintesis 
yang berfungsi sebagai penyerap karbon di lautan melalui proses biologis yang kemudian disimpan dan dialirkan, salah satunya dalam bentuk biomassa (Fourqurean et al., 2012).

Menurut Fourqurean et al. (2012), 83.000 metrik ton karbon dapat diserap padang lamun dalam setiap kilometer persegi. Nilai ini lebih besar dari kemampuan hutan menyerap karbon sebesar 30.000 metrik ton dalam setiap kilometer perseginya. Dengan besarnya nilai karbon yang diserap padang lamun, dapat menyimpan 10 persen dari kandungan karbon di lautan di seluruh dunia. Menurut Graha et al. (2016), penelitian secara intensif dan menyeluruh terkait peranan lamun sebagai blue carbon dalam upaya mitigasi perubahan iklim juga telah dilakukan sejak 10 tahun terakhir selain hutan di daratan. Maka dari itu diperlukan suatu perhitungan nilai kerapatan, tutupan lamun, biomassa dan potensi penyimpanan karbon pada jaringan lamun Enhalus acoroides yang terdapat di Pantai Gelaman dan Pantai Alang-Alang Taman Nasional Karimunjawa Jepara.

\section{MATERI DAN METODE}

Materi yang digunakan adalah sampel lamun dan data parameter kualitas perairan yang terdapat di Pantai Gelaman Pulau Kemujan (Stasiun 1) dan Pantai Alang-Alang Pulau Karimun Besar (Stasiun 2), Taman Nasional Karimunjawa. Data yang digunakan dalam penelitian ini adalah data primer utama dan primer pendukung. Data primer utama meliputi kerapatan, biomassa dan stok karbon yang ada pada lamun. Data primer pendukung meliputi parameter lingkungan di antaranya suhu, salinitas, $\mathrm{pH}$ dan ukuran butir sedimen.

Pengambilan data lamun menggunakan metode sampling mengacu pada buku panduan monitoring padang lamun LIPI dengan menggunakan metode line transect quadrant. Penelitian terbagi dalam 2 Stasiun. Setiap Stasiun akan terbagi menjadi 3 substasiun. Jarak antar substasiun adalah 50 meter dan 100 meter ke arah laut. Penentuan titik 0 dimulai dari ditemukannya jenis lamun pertama (Rahmawati et al., 2017). Pengamatan dilakukan langsung dilapangan terhadap identifikasi spesies lamun, tegakan lamun, persentase penutupan lamun dan parameter kualitas air. Pengambilan sampel lamun menggunakan transek berukuran $50 \times 50 \mathrm{~cm}$. Transek diletakan tiap titik $50 \mathrm{~m}$ ditiap substasiun dengan metode pencuplikan. Sampel lamun yang berupa herbarium basah,
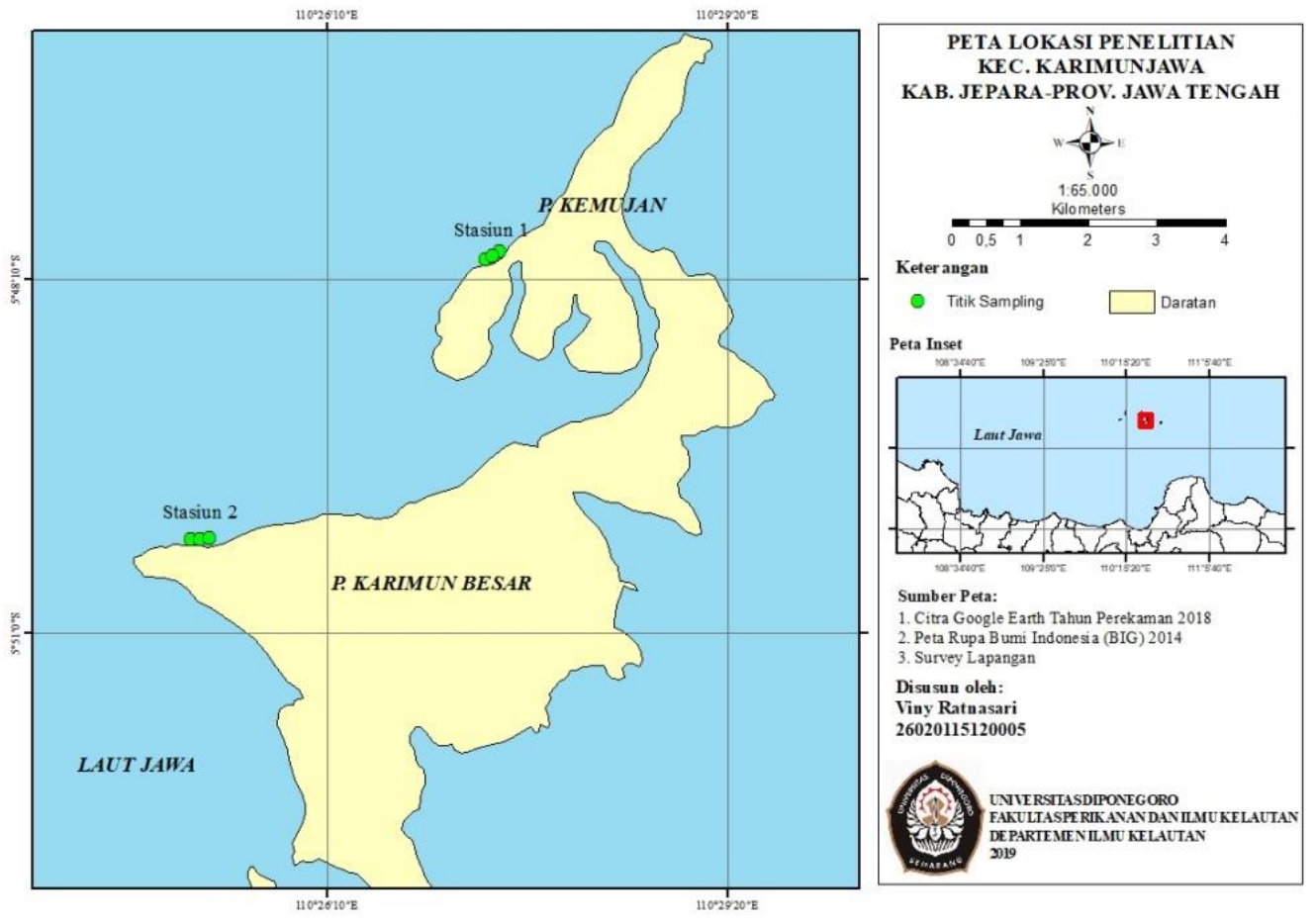

Gambar 1. Peta Lokasi Penelitian 
dipisahkan menurut jaringannya yaitu akar, rhizome dan daun kemudian dipotong menjadi bagian terkecil dan ditimbang berat basahnya. Menghitung biomassa pada lamun menggunakan metode langsung atau Destructive Sampling (Usmadi et al., 2015). Dilakukan setelah proses pengeringan dan penimbangan berat per tegakan lamun di laboratorium dengan cara memasukkan ke dalam oven pada temperatur tetap $60^{\circ} \mathrm{C}$ selama $4-5$ jam. Pengukuran karbon pada sampel jaringan lamun (daun, rhizome dan akar) dianalisis dengan menggunakan metode LOI (Loss on Ignition) (Helrich, 1990). Dalam analisis data menghitung kerapatan, persen tutupan cover dan indeks ekologi lamun. Kerapatan lamun yaitu jumlah individu lamun (tegakan) per satuan luas. Kerapatan Lamun dihitung berdasarkan rumus Brower,(1998). Persen tutupan dihitung menggunakan rumus Rahmawati et al., (2017). Indeks ekologi lamun meliputi keanekaragaman menurut rumus Brower \& Zar (1998), keseragaman menurut rumus Brower \& Zar (1998) dan dominasi menurut rumus Odum (1998). Penghitungan nilai biomassa ditunjukkan oleh persamaan menurut Duarte (1990). Perhitungan nilai kadar abu dihitung dengan persamaan oleh Helrich (1990). Perhitungan nilai bahan organik dihitung dengan persamaan oleh Helrich (1990). Nilai kandungan karbon jaringan lamun dihitung dengan persamaan Helrich (1990). Nilai estimasi kandungan karbon dihitung menggunakan persamaan Barrón et al., (2004).

\section{HASIL DAN PEMBAHASAN}

Jenis lamun yang ditemukan di Pantai Gelaman dan Pantai Alang-Alang adalah Enhalus acoroides, Cymodocea serrulata, Thalassia hemprichii, Cymodocea rotundata, Halodule uninervis dan Halophila ovalis. Hasil Kerapatan dan Tutupan cover pada Tabel 1.

Stasiun 1 menghasilkan tingkat kerapatan yang tinggi (Braun-Blanquet, 1965). Kondisi tersebut dikarenakan keadaan arus pada Stasiun 1 yang relatif tenang. Philips and Menez (1988), menyatakan bahwa lamun umumnya dapat tumbuh baik pada perairan tenang. Arus yang tenang memungkinkan lamun dapat tumbuh dan berkembang, karena akar dapat lebih mudah tertanam ke dalam substrat sehingga membantu penyerapan unsur-unsur hara sebagai sumber makanan. Stasiun 2 menghasilkan tingkat kerapatan yang lebih rendah dibandingkan Stasiun 1, hal tersebut dapat terjadi dikarenakan kondisi arus yang lebih kuat. Kondisi arus yang lebih kuat dapat membuat akar dan rimpang tidak tertanam secara maksimal dan membuat tegakan lamun rentan terlepas dari substrat (Rahman et al.,2016).

Persentase tutupan lamun totalpada Stasiun 1 dan Stasiun 2 menunjukkan bahwa nilai tutupan lamun di kedua lokasi tidak jauh berbeda.Stasiun 1 dan Stasiun 2 memiliki kondisi padang lamun yang tergolong sangat padat (Pandungan Monitoring Padang Lamun, 2014). Tutupan lamun di lokasi sangat berkaitan dengan kerapatan, semakin tinggi tingkat kerapatan maka persentase tutupan lamun akan semakin tinggi pula (Hartati et al., 2012).

Nilai indeks keanekaragaman pada Stasiun 1 dan 2 menunjukkan keanekaragaman sedang. Semakin tinggi nilai indeks keanekaragaman menunjukan perairan tersebut stabil (Kamaruddin et al., 2016).Indeks keseragaman Stasiun 1 dan 2 tergolong tinggi. Pada Stasiun 1dan 2 tidak terjadi dominansi, tidak ada satu spesies tertentu yang mendominasi spesies lainya. Hasil ini menjadi tanda bahwa kondisi ekosistem relatif stabil. Nilai indeks dominansi akan berbanding terbalik dengan dengan nilai indeks keseragaman dan nilai indeks keanekaragaman (Odum, 1998).

Berdasarkan hasil penelitian yang telah dilakukan, terdapat perbedaaan nilai biomassa jenis lamun Enhalus acoroides di Stasiun 1 dan Stasiun 2. Hasil nilai biomassa pada stasiun 1 lebih besar dibandingkan Stasiun2. Hal ini dikarenakan kerapatan dan tutupan cover pada Stasiun 1 lebih besar. Selain itu, Perbedaan terdapatpada bagian bawah substrat dan atas substrat.Nilai biomassa yang berada pada bagian bawah substrat lebih tinggi dari pada bagian lamun yang berada pada bagian atas substrat. Hal ini sesuai dengan pernyataan Hemminga and Duarte (2000),bahwa biomassa lamun pada umumnya lebih besar tersimpan pada bagian bawah substrat (below ground) dibandingkan dengan bagian atas substrat (above ground). Dikarenakan rhizome mengandung banyak zat pati dan unsur hara dimana zat tersebut didistribusikan dari hasil fotosintesis yang disimpan pada bagian dibawah substrat, sehingga biomassa pada rhizomedibawah substrat lebih tinggi dibandingkan dengan jaringan lainnya (Erftemeijer et al.,1993). 
Berdasarkan hasil penelitian didapatkan estimasi karbon Enhalus acoroides memiliki kandungan karbon lebih besar pada bagian bawah substrat dibandingkan bagian atas substrat. Tingginya nilai karbon bawah substrat disebabkan oleh karbon bawah substrat tidak terlalu terpengaruh oleh pengaruh fisik lingkungan, sebagaimana estimasi karbon yang ada di bagian atas substrat (Supriadi, 2012). Menurut Grimsditch (2013), potensi penyimpanan karbon pada bawah substrat berpeluang akan tersimpan lebih lama dan terus bertambah. Bagian bawah substrat memiliki cadangan karbon lebih besar sebanyak $15-50 \%$ dari produktivitas primer (NPP) (Rahmawati dan Kiswara, 2012)

Nilai estimasi karbon tertinggi terdapat pada Stasiun 1 yang terletak di perairan pantai Gelaman. Karena Stasiun 1 memiliki kerapatan dan persentase lamun yang lebih besar

Tabel 1. Hasil Kerapatan (ind $/ \mathrm{m}^{2}$ ) dan Tutupan (\%) Lamun di Lokasi Penelitian

\begin{tabular}{|c|c|c|c|c|}
\hline \multirow{2}{*}{ Jenis Lamun } & \multicolumn{2}{|c|}{ Stasiun 1} & \multicolumn{2}{|c|}{ Stasiun 2} \\
\hline & (ind $/ \mathrm{m}^{2}$ ) & (\%) & (ind $\left./ \mathrm{m}^{2}\right)$ & (\%) \\
\hline E. acoroides & 191 & 18.75 & 110 & 11.74 \\
\hline C. serrulata & 653 & 21.21 & 403 & 14.58 \\
\hline T. hemprichii & 244 & 16.48 & 177 & 9.28 \\
\hline C. rotundata & 107 & 8.71 & 283 & 10.11 \\
\hline H. uninervis & 40 & 3.61 & 99 & 4.36 \\
\hline H. ovalis & - & - & 63 & 1.70 \\
\hline$\Sigma$ & 1235 & 68.76 & 1135 & 51.78 \\
\hline$X$ & 247 & 13.75 & 189 & 8.63 \\
\hline
\end{tabular}

Tabel 2. Nilai Biomassa $\left(\mathrm{gbk} / \mathrm{m}^{2}\right)$ lamun Enhalus acoroides di lokasi penelitian

\begin{tabular}{ccccc}
\hline \multirow{2}{*}{ Stasiun } & \multirow{2}{*}{ Sub Stasiun } & \multicolumn{3}{c}{ Total Biomassa } \\
\cline { 3 - 5 } & & Bawah Substrat & Atas Substrat & Total \\
\hline \multirow{2}{*}{1} & a & 192,95 & 83,53 & 276,48 \\
& b & 198,43 & 138,79 & 337,22 \\
& c & 446,34 & 208,13 & 654,47 \\
2 & Total & 837,73 & 430,44 & 1268,17 \\
\hline \multirow{2}{*}{2} & a & 257,78 & 140,03 & 397,81 \\
& b & 137,79 & 88,61 & 226,40 \\
& c & 228,90 & 71,32 & 300,22 \\
& Total & 624,47 & 299,96 & 924,43 \\
\hline
\end{tabular}

Tabel 3. Nilai karbon $\left(\mathrm{gC} / \mathrm{m}^{2}\right)$ lamun Enhalus acoroides di lokasi penelitian

\begin{tabular}{ccccc}
\hline \multirow{2}{*}{ Stasiun } & \multirow{2}{*}{ Sub Stasiun } & \multicolumn{3}{c}{ Total Stok Karbon } \\
\cline { 3 - 5 } & & Bawah Substrat & Atas Substrat & Total \\
\hline \multirow{2}{*}{1} & a & 44,90 & 37,13 & 82,03 \\
& b & 62,50 & 42,93 & 105,44 \\
& c & 139,68 & 30,66 & 170,34 \\
& Total & 247,08 & 110,72 & 357,80 \\
\hline \multirow{2}{*}{2} & a & 95,31 & 64,36 & 159,67 \\
& b & 58,92 & 15,31 & 74,23 \\
& c & 18,66 & 22,14 & 40,80 \\
& Total & 172,90 & 101,81 & 274,71 \\
\hline
\end{tabular}


dengan Stasiun 2. Hal ini disebabkan oleh adanya perbedaan kondisi parameter lingkungan pada perairan tempat lamun tersebut tumbuh. Parameter tersebut dapat berupa parameter fisik maupun kimia, di mana setiap perairan memiliki karakteristik tersendiri karena adanya faktor-faktor yang dapat mempengaruhi kondisi di perairan tersebut (Papilo et al., 2015).

\section{KESIMPULAN}

Berdasarkan hasil penelitian yang telah dilakukan, kerapatan lamun total di Pantai Gelaman sebesar $1235 \mathrm{ind} / \mathrm{m}^{2}$ dan nilai total tutupan lamun sebesar $68,76 \%$. Kerapatan lamun total di Pantai Alang-Alang sebesar $1135 \mathrm{ind} / \mathrm{m}^{2}$ dan nilai total tutupan lamun sebesar $51,78 \%$. Nilai biomassa lamun Jenis Enhalus acoroides di Pantai Gelaman sebesar $422,72 \mathrm{gbk} / \mathrm{m}^{2}$ dan Pantai Alang-Alang sebesar $308,14 \mathrm{gbk} / \mathrm{m}^{2}$. Nilai estimasi karbon lamun jenis $E$. acoroides di Pantai Gelaman sebesar $119,27 \mathrm{gC} / \mathrm{m}^{2}$ dan Pantai Alang-Alang sebesar $91,57 \mathrm{gC} / \mathrm{m}^{2}$.

\section{DAFTAR PUSTAKA}

Barrón, C., Marbà, N., Terrados, J., Kennedy,H., Duarte, C.M. 2004. Community Metabolism and Carbon Budget Along a Gradient of Seagrass (Cymodocea nodosa) Colonization. Limnology and Oceanography, 49(5):1642-1651..

Brower, J.E., Zar, J.H. \& Von Ende, C.N. 1998. Field and Laboratory Methods for General Ecology.3rd ed. Brown Publisher, USA, p 345.

Duarte, C.M., 1990. Seagrass nutrient content. Marine ecology progress series. Oldendorf, 6(2), pp.201-207.

Erftemeijer, P.L., Osinga, R. \& Mars, A.E., 1993. Primary production of seagrass beds in South Sulawesi (Indonesia): a comparison of habitats, methods and species. Aquatic Botany, 46(1):67-90.

Fourqurean, J.W., Duarte, C.M., Kennedy, H., Marbà, N., Holmer, M., Mateo, M.A., Apostolaki, E.T., Kendrick, G.A., Krause-Jensen, D., McGlathery, K.J. \& Serrano, O., 2012. Seagrass ecosystems as a globally significant carbon stock. Nature geoscience, 5(7):505-509.

Graha, Y.I., Arthana, I.W. \& Karang, I.W.G.A., 2016. Simpanan karbon padang lamun di kawasan pantai sanur, kota denpasar. Ecotrophic: Jurnal IImu Lingkungan, 10(1):46-53.

Hartati, R., Junaedi, A., Hariyadi, H. \& Mujiyanto, M., 2012. Struktur Komunitas Padang Lamun di Perairan Pulau Kumbang, Kepulauan Karimunjawa (Seagrass Community Structure of Kumbang Waters-Karimunjawa Islands). IImu Kelautan: Indonesian Journal of Marine Sciences, 17(4):217-225.

Helrich, K. 1990. Method of Analysis of The Association of Official Analytical Chemists. Fifteenth Edition. Virginia.

Hemminga, M.A., \& Duarte, C.M. 2000. Seagrass Ecology. Australia: Cambridge University Press.

Kamaruddin, Z.S., Rondonuwu, S.B \& Maabuat, P.V. 2016. Keragaman Lamun (Seagrass) di Pesisir Desa Lihunu Pulau Bangka Kecamatan Likupang Kabupaten Minahasa Utara, Sulawesi Utara. Jurnal MIPA. Unsrat, 5(1):20-24.

Odum, E.P. 1998. Dasar-dasar Ekologi.3rd ed. Universitas Gadja Mada, Yogyakarta.

Papilo, P., Kunaifi, K., Hambali, E., Nurmiati, N. \& Pari, R.F., 2015. Penilaian Potensi Biomassa Sebagai Alternatif Energi Kelistrikan. Penelitian dan Aplikasi Sistem dan Teknik Industri, 9(2):164-176.

Philips, C.R. \& Meñez E.G. 1988. Seagrass. Washington D.C.: Smith Sonian. Institutions Press.

Rahman, A.A., Nur, A.I., \& Ramli, M. 2016. Studi Laju Pertumbuhan Lamun (Enhalus acoroides) di Perairan Pantai desa Tanjung Tiram Kabupaten Konawe Selatan. Jurnal Sapa Laut.,1(1):1016

Rahmawati, S., Irawan, A., Supriyadi I.H \& Azkab M.H. 2017. Panduan Monitoring Padang Lamun CRITC COREMAP CTI LIPI. 
Tuwo, A. 2011. Pengelolaan Ekowisata Pesisir dan Laut; Pendekatan Ekologi, Sosial Ekonomi, Kelembagaan dan Sarana Wilayah. Brilian Infernasional, Makassar.

Usmadi, D., Hidayat, S., Yuzammi, Y. \& Asikin, D., 2015. Potensi Biomassa Dan Cadangan Karbon Kebun Raya Balikpapan, Kalimantan Timur. Buletin Kebun Raya, 18(1):01-14. 